\title{
Tilting at windmills no longer: a data-driven discussion of DTC DNA ancestry tests
}

\author{
Jennifer K. Wagner, JD, PhD, ${ }^{1}$ Jill D. Cooper, $\mathrm{MPH}^{2}{ }^{2}$ Rene Sterling, $\mathrm{PhD}, \mathrm{MHA}^{3}$ and \\ Charmaine D. Royal, MS, PhD²
}

\begin{abstract}
Purpose: Discussions about direct-to-consumer (DTC) DNA ancestry tests have to date been based primarily on conjectures, speculation, and anecdotes, despite the industry being more than a decade old. Representative, empirical data on consumer characteristics; motivations and expectations for testing; intended uses for the information; understanding of results; and behavioral and psychological reactions to the tests are absent. Although the 2010 American Society of Human Genetics white paper clarifies the number and some general characteristics of companies marketing and selling DNA ancestry tests, additional data about the industry's practices have been unavailable.

Methods: To promote a data-driven discussion of the DNA ancestry testing industry, we conducted a systematic investigation to identify companies selling DNA ancestry tests and conducted an empirical study of the industry's practices using data collected from each company's website.
\end{abstract}

Results: Here, we present a wealth of data, including an updated directory of companies, marketing slogans, product types and names, range of prices, diversity of reporting and representing results, noted benefits and limitations of testing, and a host of website practices.

Conclusion: The tremendous diversity of tests, information, and practices of companies in the DNA ancestry sector should be considered when policies for best practice guidelines or regulatory oversight are being developed.

Genet Med 2012:14(6):586-593

Key Words: direct-to-consumer; DNA ancestry; genetic ancestry; genomic ancestry

\section{INTRODUCTION}

The marketing and sale of genetic tests direct-to-consumers (DTCs) have stirred much controversy. Proponents of DTC genetic testing have argued that individuals-not just patientshave a right to their genetic and genomic information. ${ }^{1}$ Many opponents have argued that the DTC genetic testing industry fails to provide consumers with adequate information about the tests, data privacy protections, and counseling services. ${ }^{2,3}$ Recent reports found that the DTC genetic testing websites are designed at inappropriate reading levels and generally lack user-friendly tools. ${ }^{4}$ Reviews of corporate practices in the personal genomics industry to date have, however, been limited in scope, often narrowing their focus to health-related testing ${ }^{3-5}$ or nutrigenomics testing. ${ }^{6}$ The tabulation of companies providing DTC genetic testing has been challenging, as conflicting information in the literature ${ }^{2,3,5,7}$ demonstrates. At least two sources of confusion exist in the literature: (i) inconsistent or evolving definitions of DTC (e.g., a website may market tests DTC without actually selling them or a company such as GeneDx might not view itself as having offered or as currently offering genetic tests DTC but might nevertheless be characterized by others as doing so; ${ }^{2}$ Sherry Bale, president and clinical director of GeneDx, personal communication, 21 September 2010) and (ii) nondisclosure of the actual companies investigated in published content analyses (e.g., the study reported in ref. 4 performed content analysis of 29 unidentified companies, making it difficult to verify findings).

Expert discussions and formal reviews of the DTC genetic testing industry have generally omitted an entire sector of the industry: companies that offer DNA ancestry tests. ${ }^{4,8-10}$ This is typically done on the justification that ancestry tests are nonmedical. Although no empirical investigations of the DNA ancestry testing websites or of corporate practices have been published to date, many scholars have discussed the scientific, ethical, legal, and social implications of DNA ancestry information. ${ }^{11-36}$ The DNA ancestry testing industry, which markets and sells a variety of genetic and genomic ancestry tests DTC, is now 11 years old. Family Tree DNA offered the first DTC genetic ancestry test in 2000, and DNAPrint Genomics offered the first genomic ancestry test in 2002. The industry grew to $11 \mathrm{com}-$ panies by 2004 (ref. 16) and to 14 companies by 2008 (ref. 22). By 2010, there were 38 companies selling a wide variety of DNA ancestry products, packages, and services. ${ }^{33,34}$ More than 1 million individuals have reportedly purchased the tests since 2002 (ref. 37), although the accuracy of this figure is unknown. The characteristics of the individuals purchasing these tests

${ }^{1}$ Center for the Integration of Genetic Healthcare Technologies, University of Pennsylvania, Philadelphia, Pennsylvania, USA; ${ }^{2}$ Institute for Genome Sciences \& Policy, Duke University, Durham, North Carolina, USA; ${ }^{3}$ Center for Genomics and Society, University of North Carolina, Chapel Hill, North Carolina, USA. Correspondence: Charmaine D. Royal (charmaine.royal@duke.edu) 
are also not known with any level of certainty. Moreover, our knowledge of the companies of the industry, products offered, advertising claims made, and representation of results reported remains rudimentary and largely anecdotal.

Given the acknowledged wide variability of business practices of DTC genetic testing companies ${ }^{4}$ and the recognized role that the particular design, marketing, and delivery of a test (i.e., the sociotechnical architecture) plays in structuring its implications, ${ }^{38}$ it is unfortunate that no empirical data are available for this entire sector of the DTC genetic testing industry. The generation of an updated directory of DNA ancestry testing companies by the American Society of Human Genetics in 2010 was an important first step toward enhancing our understanding of this industry. ${ }^{33}$ Here, we build on that work and provide the first systematic review of this sector of the DTC genetic testing industry.

\section{MATERIALS AND METHODS}

For the initial identification of DNA ancestry testing companies, we employed methods described in detail elsewhere. ${ }^{6}$ We conducted a comprehensive search for DNA ancestry testing companies using the Internet, news media, and other popular press, employing Google, Yahoo, and Lexis/Nexis Academic. Terms related to genetics, ancestry, and testing were combined to form three-word search strings for use in each of the search engines. Seven unique search strings were used: DNA Ancestry Test Service Profile Scan, Mitochondrial Test Service Profile Scan, Y-Chromosome Test Service Profile Scan, Gene Ethnic Race Test Service Profile Scan, Heritage Lineage Genealogy Test Service Profile, Ancestry Testing, and Genealogy Profile.

Upon performing a search with these search strings in Google and Yahoo, the first three pages of search results were printed. There were 10 uniform record locators (URLs) per page for each of the seven search term strings used. A total of 420 URLs were then followed to identify companies selling DTC DNA ancestry tests. All functional websites that were in English and that appeared to be selling a genetic ancestry test were followed for further analysis. Searches performed in Lexis/Nexis Academic included the following restrictions: time period of 1995-2010, English language, major US and world publications, US and world news transcripts, and US ethnic news and publications. All results from the Lexis/Nexis Academic searches were reviewed. To be eligible for inclusion as a site, the organization needed to sell—not merely market, advertise, or otherwise promote-at least one ancestry test. Corporate websites were considered to sell ancestry testing services if consumers could purchase ancestry tests by entering their contact, delivery, and payment information on its website (e.g., through an online shopping cart or order form). When a website directed consumers to another website or company selling ancestry testing services, it was defined as a promoter company and was not included for archiving or further analysis.

Internet Researcher 2.1, developed by Zylox Software (http:// www.zylox.com/register.shtm), was used to archive all functional websites identified and meeting the eligibility criteria (including ones later found to have dissolved) under their domain names. Use of this software enabled us to create a fixed cross-section of the industry by archiving all components of a website (pages, images, links, and objects) while maintaining the referential integrity among all sections to allow for navigation through the website even when offline or at a later date. Only links with the same domain name were archived for our analysis (that is, if clicking on a word, image, or link led the consumer away from the main website and to a different site domain, that site was not archived).

Data from the archived websites were collected for content analysis, and the sites were coded independently. Content analysis included the following variables of interest: organization characteristics (start date, geographic location, company's product orientation, tag line/motto, laboratory accreditation, privacy policies, other DNA tests offered); product characteristics (ancestry tests offered, price, discounts mentioned, type of specimen collected, type of analysis performed, educational resources offered); general discussion of benefits, limitations, and risks; and materials provided with the ancestry test. To compare products sold internationally, all prices were converted to US dollars (\$) using currency conversion rates as of 18 April 2010 (which most closely approximate the value in US dollars that would have applied at the time the websites were archived). As shown in Table 1, all website domains for active companies were searched again on 20 April 2011 to facilitate the most accurate reporting of the industry. All investigators participated in the development of the coding scheme; however, for coding consistency, only one researcher performed the coding and content analysis of the data. The investigative team met regularly to discuss the coding activities and data analysis and resolve discrepancies. Data were collected and analyzed in Microsoft Access 2007.

To complement the content analysis of the websites selling DNA ancestry tests, we sought input directly from the DNA ancestry testing companies on their corporate practices and perspectives of the industry. To do so, we designed and administered an online questionnaire using Survey Monkey (Palo Alto, CA). The questionnaire explored details about the company (e.g., how long it has been in business, where it was formed, whether it has any academic affiliations); the company's consumers (e.g., how many have purchased their tests, whether there is an apparent or perceived targeted demographic for the company); the company's website (e.g., what features are provided on the site, whether video tutorials are provided, what navigational tools are available); the reporting and representation of results (e.g., by mail or Internet, through textual or visual/graphical illustrations); and industry standards and customs. Each company in the industry was invited using the e-mail address or "Contact us" forms provided on the company's website. Survey administration was open between 4 February 2011 and 1 April 2011. Unfortunately, owing to low levels of participation and response (less than one-third of the companies invited logged onto the survey and only two companies completed the survey), we are unable to report any results here. 
Table 1 Marketing slogans/prominent tag lines

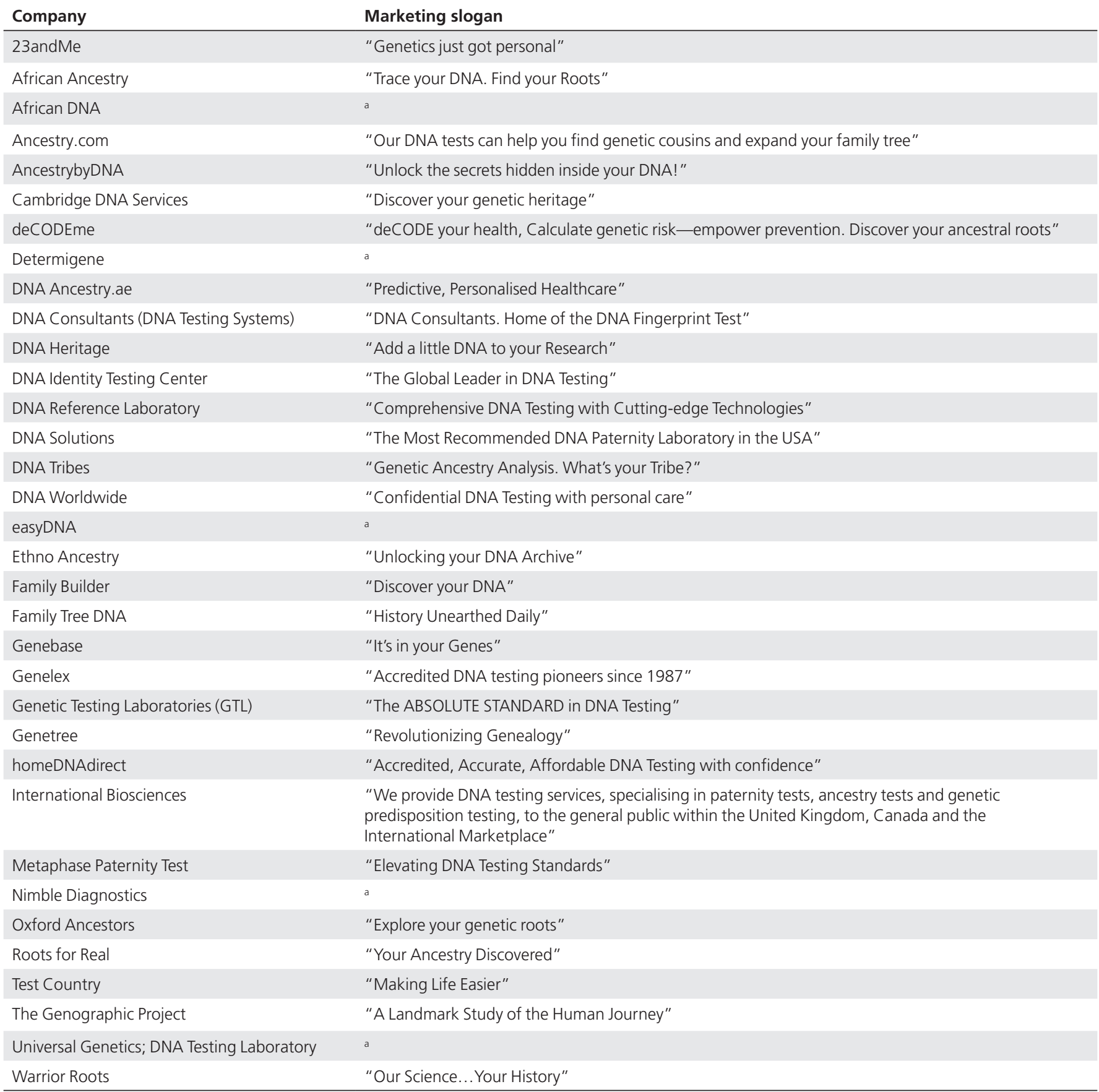

Marketing slogans or prominent tag lines used by the companies on or about April 2010, which was when all the websites were archived and data were collected. ${ }^{a}$ No marketing slogan or prominent tag line was identified from the archived website.

\section{RESULTS}

A total of 35 DTC DNA ancestry testing companies were identified and analyzed (as reported in the directory, see Supplementary Table S1 online); however, during the preparation of this paper, two additional companies were discovered (Accu-metrics Viaguard and DNA 11). No data were collected from these two websites, and therefore they were not included in any analyses or results. The discrepancy between the number of companies identified and the 38 companies reported by Royal et al. ${ }^{33}$ last year does not reflect a clear shrinkage of the industry as a cursory subtraction might suggest. Rather, a few notable distinctions between the table of the industry shown in Royal et al. ${ }^{33}$ and that reported here must be highlighted. Six companies reported by Royal et al..$^{33}$ are not included in the present list for four distinct reasons: (i) DNA Direct and Pathway Genomics no longer sell genetic tests DTC; (ii) Argus BioSciences and 
Family Genetics Limited no longer have functional websites; (iii) Paternity Experts no longer sells DNA ancestry (but does sell familial or relationship) tests; and (iv) DNA Heritage ceased operations on 19 April 2011 and began transferring its domains to Family Tree DNA (http://www.dnaheritage.com). Although Paternity Experts and DNA Heritage no longer sell DNA ancestry tests, these companies were included in the analyses and results with the other companies active in April 2010. In addition, three companies not reported by Royal et al. ${ }^{33}$ are now reported: Nimble Diagnostics, Accu-metrics (Viaguard), and DNA 11 Inc. As of 16 April 2011, there were four known promoter websites of the DNA ancestry testing industry: (i) http:// www.DNA-Roots.com (which automatically directs prospective customers to AncestrybyDNA); (ii) http://www.dnanow. com (which automatically directs prospective customers to DNA Solutions); (iii) http://worldfamilies.net (which ultimately directs prospective customers to Family Tree DNA); and (iv) http://www.dnaancestryproject.com (which appears to be an alternative website for Genebase). To reiterate, the content analysis performed on the websites and subsequently all results discussed here exclude these promoter websites.

The DNA ancestry testing companies employ a variety of marketing slogans and prominent tag lines (Table 1). The products are named similarly from company to company (see Supplementary Table S2 online). The industry has offered 151 products or packages, consisting of 41 mitochondrial DNA (mtDNA) products, 57 Y-chromosome products, 28 autosomal products, 22 packages that combine mtDNA and Y-chromosome products, and three packages that combine mtDNA, Y-chromosome, and autosomal products. These types of individual products or packages have been offered, respectively, by $80 \%(n=28), 80 \%(n=28), 49 \%(n=17), 43 \%(n=$ $15)$, and $9 \%(n=3)$ of the companies in the sector. The median prices for these individual or packaged products are $\$ 195, \$ 199$, $\$ 255$, \$389, and $\$ 399$, respectively. Price comparisons are subject to an important caveat. Providing an accurate summary of the prices for DNA ancestry products is a challenging endeavor because products are not apples-to-apples comparisons. Even when one looks at only one type of test (e.g., an mtDNA, nonrecombining $\mathrm{Y}$ (NRY), or autosomal test), the products may not assay the same number or type of loci. For example, not all autosomal tests are admixture tests or report proportional ancestry. Moreover, there are a number of "add-on" products available to consumers only with the concurrent or previous purchase of a separate "stand-alone" product (e.g., particular markers relevant to a particular haplogroup may be added after the initial haplogroup has been determined). Similarly, several companies sell packages or combinations of tests that may or may not be sold separately (e.g., the ancestry service provided by 23 andMe analyzes mtDNA, NRY, and autosomal DNA but does not permit consumers to purchase these tests à la carte). Additionally, some of the DNA tests are sold in combination with professional genealogical services (e.g., Gpkg + mtDNA sold by African DNA). The prices are thus not necessarily restricted to DNA analysis. Subject to those aforementioned considerations, product prices are included in Supplementary Table S2 online and are displayed in Figure 1.

DNA ancestry companies report results to consumers using a variety of methods; however, not every company provides sample results or examples on the website that are viewable to

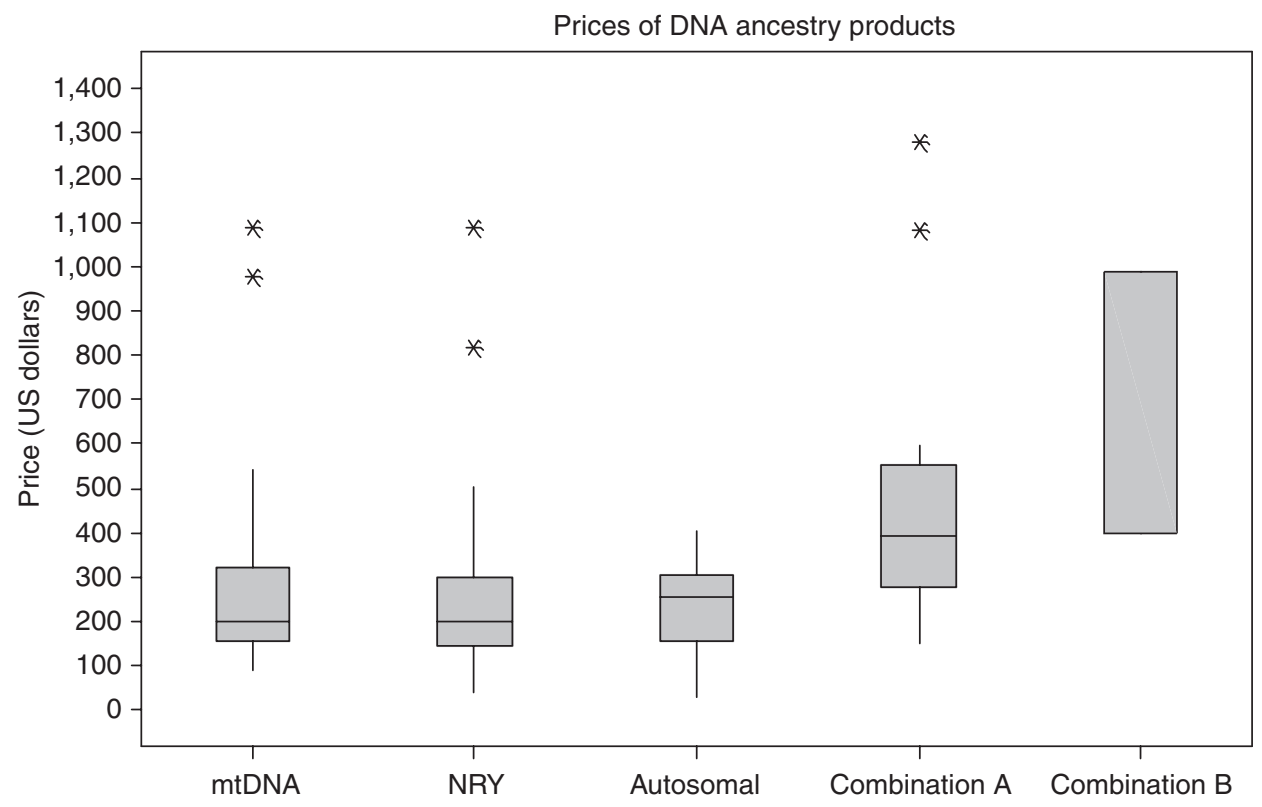

Figure 1 Price summary of DNA ancestry products. The box plot displays the range of prices for the various types of tests as shown in Supplementary Table S2 online. "Combination A" refers to packages including mtDNA and NRY analyses only. "Combination B" refers to those including mtDNA, NRY, and autosomal analyses. The outliers are products sold by African DNA and DNA Ancestry.ae. mtDNA, mitochondrial DNA; NRY, non-recombining Y. 


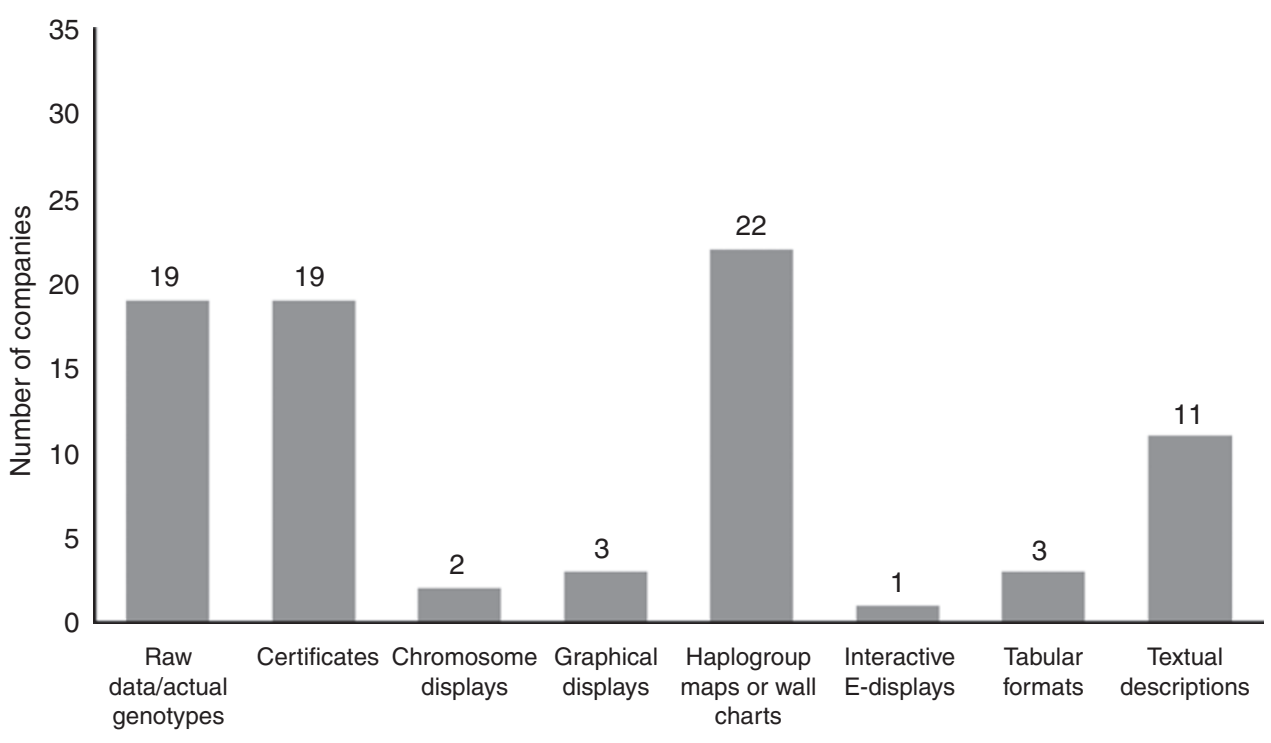

Commonly used methods for reporting or representing results

Figure 2 Diversity in representation of DNA ancestry test results.

consumers prior to purchase. Thus, these data-collected from the website as it appears to prospective consumers-may not accurately reflect the actual practices of the companies and may not capture all of the diversity in the representation and reporting of results. Figure 2 summarizes the number of companies providing DNA ancestry test results using eight methods or formats. Wall charts and haplogroup maps are the most commonly used format, although there is no consensus on where Africa is displayed on the map (e.g., on the leftmost edge or in the center). Five companies provide a social-networking (or "relative-finder") feature.

Table 2 displays the number of companies (and proportion of the industry) that reported particular benefits and limitations (or risks) of DNA ancestry testing. Eight companies (22.9\% of the industry) did not report any benefits and 23 companies (65.7\% of the industry) did not report any limitations or risks on their websites. Only nine companies $(25.7 \%$ of the industry) expressly limit the "intended use" of DNA ancestry tests to recreational, educational, or entertainment purposes. As with the data reported on the representation of results above, the data reported here on benefits, limitations, and risks were collected from sections of the websites accessible to prospective consumers and may not be comprehensive (additional information might be reported to the consumers after a product is purchased). Other information provided by the companies, such as whether the laboratory used to conduct the assay is certified according to the Clinical Laboratory Improvement Amendments of 1988 certified or accredited by the American Association of Blood Banks, is reported in Table 3. Notably, although it might be useful to know whether accreditation status is predictive of any disclosure practice, such analysis of the data collected on disclosure
Table 2 Benefits, limitations, and risks of testing as indicated on companies' websites

\begin{tabular}{lc}
$\begin{array}{l}\text { Benefits and limitations of } \\
\text { testing }\end{array}$ & $\begin{array}{c}\text { No. of companies } \\
\text { (proportion of industry) }\end{array}$ \\
\hline Benefits & $27(77.1 \%)$ \\
Learn about ancient ancestors & $21(60.0 \%)$ \\
Fill gaps in lineage & $11(31.4 \%)$ \\
Find relatives & $7(20.0 \%)$ \\
Determine group membership & $6(17.1 \%)$ \\
Learn more about who you are as a & $6(17.1 \%)$ \\
person & $6(17.1 \%)$ \\
Social networking & $2(5.7 \%)$ \\
Obtain print documentation & $1(2.9 \%)$ \\
Have fun & $12(34.3 \%)$ \\
Limitations or risks & $9(25.7 \%)$ \\
Results are for recreational/ & \\
educational/entertainment use only & $8(22.9 \%)$ \\
Results are not a complete lineage & $1(2.9 \%)$ \\
Database of genetic markers not & $1(2.9 \%)$ \\
globally representative & \\
Results may be unexpected or & \\
surprising &
\end{tabular}

A total of 35 companies were included in this analysis. All the companies listed in this table were analyzed except Accu-metrics (Viaguard) and DNA 11 Inc. (both of which were not discovered until this paper was in preparation) and with the additions of Paternity Experts and DNA Heritage (which were included in the analysis but no longer appear to be selling DNA ancestry tests). Data reflect information found on the companies' websites on or about April 2010. The benefits and limitations listed here are not necessarily verbatim from the sites. Of the 35 companies analyzed, 8 (22.9\%) did not state any benefits and $23(65.7 \%)$ did not state any limitations or risks related to DNA ancestry testing. 
Table 3 Additional information provided on companies' websites

\begin{tabular}{lc} 
Item of interest & $\begin{array}{c}\text { No. of companies } \\
\text { (proportion of industry) } \\
\text { addressing item of } \\
\text { interest }\end{array}$ \\
\hline CLIA-certified laboratory & $5(14 \%)$ \\
\hline AABB-accredited laboratory & $15(43 \%)$ \\
\hline Number of loci assayed & $26^{\mathrm{a}}(74 \%)$ \\
\hline Glossary of terms & $15(43 \%)$ \\
\hline Educational page & $25(71 \%)$ \\
\hline Policy for handling of specimens & $15(43 \%)$ \\
\hline Policy for handling of data & $22(63 \%)$ \\
\hline Terms of service & $24(69 \%)$ \\
\hline
\end{tabular}

Particular items of interest and the number of companies (and proportion of the industry, $N=35$ ) that provide that particular information as of April 2010.

AABB, American Association of Blood Banks; CLIA, Clinical Laboratory Improvement Amendments.

${ }^{2}$ The number of loci for at least one product sold by each of these companies was disclosed.

of accreditation status may not provide meaningful results (e.g., a company might be certified yet not disclose such certifications online or a company processing saliva samples but not blood samples might have sound legal and business justifications for not seeking particular accreditations).

\section{DISCUSSION}

To date, the scholarly literature has been dominated by criticisms of the DNA ancestry testing industry. For example, the industry has been criticized for "selling the imprimatur of science" and accused of "skip[ping] the caveats... and...invoke[ing] science's power without accepting its limits".22 A number of scholars have criticized the industry for engaging in "misleading practices" and concurrently chided the "scientific community" for failing to make "the limitations and potential dangers" clear. ${ }^{19}$ More recently, some of these scholars have called for federal regulation of the industry to set mandatory standards for the industry. ${ }^{26}$ The American Society of Human Genetics summary statement ${ }^{39}$ and white paper ${ }^{33}$ on genetic and genomic ancestry inference not only provided broad recommendations but also acknowledged that more tangible guidance is needed. It is important to note that the salient caveats and limitations of DTC DNA ancestry testing, as well as specific suggestions for enhancing accountability within the industry, were previously articulated by pioneers of the industry. ${ }^{16}$ Still, there remains a clear need for adequate practical guidelines to achieve heightened consumer protections through voluntary refinement of industry practices. To a large degree, industry advocates and critics alike have been restricted by lack of empirical data on the current state of the industry. The data provided here begin to fill that gap and promote a data-driven discussion. These rich data from the companies' websites provide a snapshot of the state of the industry as of April 2010 and will help to shape practical recommendations.
This research provides actual and prospective consumers, consumer advocates, and policy makers with a wealth of data to make better-informed decisions. The data, particularly those shown in Figure 1 and Supplementary Table S2 online, demonstrate that there is substantial variability in prices and products and, accordingly, that there are many potential pitfalls when comparison shopping or making industry-wide generalizations. These data are of immeasurable importance to consumers and their advocates. For example, interested parties may now recognize that price is a reflection not only of the quality or complexity of the DNA analysis offered but also of non-DNA services bundled with the DNA analysis-such as professional genealogical research assistance or the production of unique pieces of artwork-as well as a reflection of profit margins sought. The relative frequency with which various methods for representing results are used, as shown in Figure 2, is not an indication that a more frequently used method is proving better than another, as the representation of results is necessarily context dependent (e.g., use of a chromosomal display would be confusing and unnecessary if the consumer purchased an mtDNA test). The diversity in products also underscores the care that must be exercised when attempting to make product comparisons within the same company or between companies. Well-intentioned but impractical policy recommendations may be avoided if this variability is kept in mind and if flexible standards (as opposed to rigid rules or mandatory methodologies) are established. For example, although Table 2 summarizes the variability in the industry's disclosure of benefits, limitations, and risks of testing, it is important to keep in mind that this information may vary contextually, as the information derives from the type of product offered, the methods used to perform the analysis, and the chosen representation and reporting of the results. The diversity of products available suggests that a failure to find uniform industry practices (e.g., for advertising, return or representation of results, or even reported benefits, risks, and limitations) may not be an accurate gauge of how well the industry is performing in terms of fair practices and suggests that mandatory industry-wide reporting rules may be inappropriate (e.g., establishing a mandatory reporting of confidence intervals may not make sense for all products, given the diverse methodologies employed by the companies).

The data we report are basic types of information that should be easily derived from the websites. However, the data collection was challenging, reiterating the need for the industry to improve its communications with prospective or potential consumers. A few practical recommendations emerge from this content analysis. First, some of the websites were difficult to navigate and could be improved by simplified organization with clearly delineated pages and fully functional search engines. The language on many sites was more complex than consumerprotection laws (e.g., Pennsylvania's Plain Language Consumer Contract Act) allow. It would be reasonable to encourage companies to review the information conveyed on the websites-particularly the terms-of-service agreements and the "click wrap" language required for purchase-so that it is comprehensible 
at an eighth-grade reading level and clearly and simply defines scientific jargon. A company neglects this issue at its own peril, as courts not only may refuse to enforce limitations of liability imposed by the terms of service but also may impose hefty treble damages pursuant to state-specific consumer-protection statutes if consumers seek legal remedy. Second, knowing (i) the diverse ways in which results can be represented, illustrated, and reported and (ii) that prospective consumers may come to the company with varying motivations and expectations, companies could minimize the chance of consumer dissatisfaction (e.g., after paying for a test that did not provide the consumer with the information he or she sought) and misinterpretation of results if the consumer could view examples of results and accompanying explanations or interpretations of those results prior to purchase. Third, although many companies do a commendable job of disclosing the number of loci assayed by their products, many companies lag in disclosure of details regarding their reference databases, the particular loci assayed, and citations for the peer-reviewed scientific publications that are the foundation of their products. Although it is possible that only a subset of consumers will have sufficient interest or training to access and understand peer-reviewed publications, the availability of this information would assist those looking out for the consumer's interests (e.g., legal counsel or medical providers who might otherwise be unfamiliar with DNA ancestry technologies). We join in previous recommendations for increased transparency regarding the products sold (e.g., specific loci assayed, sampling design and sizes of the reference databases, and protocols for handling consumer data after testing) and argue that it is in a company's best interest-financially and scientifically-to do so.

Based on these data and our previous research, ${ }^{30,32-36}$ we believe that specific, federal regulation of the DNA ancestry testing industry is not warranted or justifiable at this time. Consumer protections already exist in the form of generally applicable laws (e.g., e-commerce governance and general tort and contractual remedies), and genetic exceptionalism remains unjustified. There continue to be no data to support the position that potential or actual harms faced by consumers of DTC genetic tests are not adequately addressed by existing, generally applicable state and federal law. Previous recommendations suggested that the American Association of Blood Banks and the National Forensic Science and Technology Center jointly establish standards for ancestry testing and oversee laboratory accreditations. ${ }^{16}$ While no ethical or industry standards have been published, some companies in the DNA ancestry industry are accredited by the American Association of Blood Banks and the Clinical Laboratory Improvement Amendments, as shown in Table 3. We call on the International Society of Genetic Genealogy (ISOGG) to take a leadership role in (i) articulating an ethical code to guide the practices of the industry it advocates and (ii) developing a consumer guide to provide prospective consumers of the DNA ancestry testing industry with a reliable means to compare products and companies for their varying consumer motivations and interests. Moreover, we reiterate the need for a roundtable discussion (as recommended by the American Society of Human Genetics white paper) to better engage the many parties with diverse needs for and interests in DNA ancestry inference and testing. Such a roundtable will be successful in developing best practice guidelines for DNA ancestry testing only if all parties approach the project in good faith.

While policymakers often seek straightforward descriptive statistics for convenient reference in policy discussions, the data reported here are not conducive to such distillation. For example, information available to prospective consumers (i.e., disclosures accessible prior to purchase) may not be indicative of the totality of the information available to actual consumers (i.e., disclosures accessible during or after the DTC transaction). It would be tempting to offer comparisons of practices between or among groups of companies (e.g., a comparison of disclosures made by companies using accredited laboratories versus those using unaccredited laboratories, or a comparison of practices among companies offering genetic ancestry tests versus those offering genomic ancestry tests), but we have resisted such temptations for two main reasons: (i) to maintain the integrity of the subtleties in the data collected (i.e., data integrity might be compromised if summary statistics were provided and subsequently cited casually without adequate recognition of caveats that, in our opinion, outweigh the practical value and meaning of the summary statistics) and (ii) to encourage a nuanced understanding (and discourage overgeneralizations) of this ever-changing DTC sector. Furthermore, it must be acknowledged that the data presented here remain limited in scope. Many aspects of the industry - particularly details regarding the number and demographics of consumers who have purchased the products and details regarding consumers' testing experiences, reactions to the results, uses for the information, and long-term psychological and social effects-remain unclear. Corporate practices and perspectives would have been a valuable supplement to the information publicly accessible on the corporate websites. It is unfortunate that only two companies in the industry chose to complete our survey designed to serve this purpose and inform the discussion. Without the cooperation of companies to inform investigations of the state of the industry, speculation about the potential risks and harms will continue and focus will remain on anecdotes and case studies that may not be representative of all consumers of the industry or of all consumers of a particular company (which may have a unique consumer market or clientele). As a result, the discussion of the DNA ancestry testing industry and its contextual implications may continue to be unbalanced, hampering the development of relevant and effective policies.

There are many lines of inquiry that would be both interesting and relevant to a better understanding the DNA ancestry testing sector of the personal genome industry. Notably, scholars and prospective consumers alike may be interested in learning, for example, the current price per marker analyzed, whether a company's laboratory accreditations or certifications are predictive of its disclosure practices 
(e.g., disclosures of benefits and risks), and whether consumers have access to raw genotyping results. Moreover, a welldesigned qualitative and quantitative analysis of the marketing images and advertising statements would be helpful to researchers trying to gauge consumer expectations and motivations for testing as well as reactions, attitudes, and experiences after testing. Although the rich data provided here-the first empirical data available for this sector-could not possibly satisfy the appetite for full understanding of this DTC genetic testing sector, we hope that it whets the appetite for a data-driven understanding and inspires others to investigate the many remaining questions.

\section{SUPPLEMENTARY MATERIAL}

Supplementary material is linked to the online version of the paper at http://www.nature.com/gim

\section{ACKNOWLEDGMENTS}

We sincerely thank the two unidentified DNA ancestry companies that generously provided information on their corporate practices and perspectives as part of our survey. This research was supported, in part, by the Greenwall Faculty Scholars Program in Bioethics and grant 5P50HG004488 from the Ethical, Legal, and Social Implications Research Program, National Human Genome Research Institute.

\section{REFERENCES}

1. Wolfberg AJ. Genes on the Web-direct-to-consumer marketing of genetic testing. N Eng/ J Med 2006;355:543-545.

2. Williams-Jones B. Where there's a web, there's a way: commercial genetic testing and the Internet. Community Genet 2003;6:46-57.

3. Gollust SE, Wilfond BS, Hull SC. Direct-to-consumer sales of genetic services on the Internet. Genet Med 2003;5:332-337.

4. Lachance CR, Erby LA, Ford BM, Allen VC Jr, Kaphingst KA. Informational content, literacy demands, and usability of websites offering health-related genetic tests directly to consumers. Genet Med 2010;12:304-312.

5. McBride $\mathrm{CM}$, Wade $\mathrm{CH}$, Kaphingst KA. Consumers' views of directto-consumer genetic information. Annu Rev Genomics Hum Genet 2010;11:427-446.

6. Sterling R. The on-line promotion and sale of nutrigenomic services. Genet Med 2008;10:784-796.

7. Mitchell S. No MD required: patients can order their own medical tests. WebMD Health. 20 June 2011. http://www.webmd.com/cholesterol-management/ news/20010620/no-md-required-patients-can-order-their-ownmedical-tests.

8. Secretary's Advisory Committee on Genetics, Health, and Society, SACGHS. US System of oversight of genetic testing: a response to the charge of the secretary of health and human services: report of the Secretary's Advisory Committee on Genetics, Health, and Society, 2008. http://oba.od.nih.gov/oba/SACGHS/ reports/SACGHS_oversight_report.pdf.

9. Secretary's Advisory Committee on Genetics, Health and Society. 2010. Directto-consumer genetic testing. http://oba.od.nih.gov/oba/SACGHS/reports/ SACGHS_DTC_report_2010.pdf.

10. Hudson K, Javitt G, Burke W, Byers P, and ASHG Social Issues Committee. ASHG Statement on direct-to-consumer genetic testing in the United States. Am J Hum Genet 2007;81:635-637.

11. Elliott C, Brodwin P. Identity and genetic ancestry tracing. BMJ 2002;325:1469-1471.
12. Rotimi CN. Genetic ancestry tracing and the African identity: a doubleedged sword? Dev World Bioeth 2003;3:151-158.

13. Baylis F. Blacks as me: narrative identity. Dev World Bioeth 2003;3: 142-150.

14. Johnston J. Resisting a genetic identity: the black Seminoles and genetic tests of ancestry. J Law Med Ethics 2003;31:262-271.

15. TallBear K. DNA, blood, and racializing the tribe. Wicazo SA Review 2003;18:81-107.

16. Shriver MD, Kittles RA. Genetic ancestry and the search for personalized genetic histories. Nat Rev Genet 2004;5:611-618.

17. Winston CE, Kittles RA. Psychological and ethical issues related to identity and inferring African ancestry of African Americans. In: Turner TR (ed). Biological Anthropology and Ethics: From Repatriation to Genetic Identity. State University of New York Press: Albany, NY, 2005:209-229.

18. Koerner BI. Blood feud. Wired. September 2005. http://www.wired.com/ wired/archive/13.09/seminoles.html.

19. Bolnick DA, Fullwiley D, Duster T, et al. Genetics. The science and business of genetic ancestry testing. Science 2007;318:399-400.

20. Frudakis T. The legitimacy of genetic ancestry tests. Science 2008;319:1039-1040; author reply 1039.

21. TallBear K. Narratives of race and indigeneity in the Genographic Project. J Law Med Ethics 2007;35:412-424.

22. Greely HT. Genetic genealogy: genetics meets the marketplace. In: Koenig BA, Lee SS-J, Richardson SS (eds). Revisiting Race in a Genomic Age. Rutgers University Press: New Brunswick, NJ, 2008:215-234.

23. Fullwiley $\mathrm{D}$. The biologistical construction of race: 'admixture' technology and the new genetic medicine. Soc Stud Sci 2008;38:695-735.

24. Sarata AK. Genetic Ancestry Testing: CRS Report for Congress. 12 March 2008. http://www. policyarchive.org/handle/10207/bitstreams/18866.pdf.

25. Duster T. Ancestry testing and DNA: uses, limits-and caveat emptor. GeneWatch. 2009. http://www.councilforresponsiblegenetics.org/ PageDocuments/O7HIKRKXYB.pdf

26. Lee SS-J, Bolnick DA, Duster T, Ossorio P, TallBear K. The illusive gold standard in genetic ancestry testing. Science 2009;325:38-39.

27. Nelson A. Bio science: genetic genealogy testing and the pursuit of African ancestry. Soc Stud Sci 2008;38:759-783.

28. Nordgren A, Juengst E. Can genomics tell me who I am? Essentialist rhetoric in direct-to-consumer DNA testing. New Genet Soc 2009;28:157-172.

29. Weiss KM, Long JC. Non-Darwinian estimation: my ancestors, my genes' ancestors. Genome Res 2009;19:703-710.

30. Wagner JK. Just the facts ma'am: removing the drama from DNA dragnets. NC J Law Tech 2009;11:51-101.

31. Zwart H. Genomics and identity: the bioinformatisation of human life. Med Health Care Philos 2009;12:125-136.

32. Wagner JK. Interpreting the implications of DNA ancestry tests. Perspect BiO Med 2010;53:231-248.

33. Royal CD, Novembre J, Fullerton $S M$, et al. Inferring genetic ancestry: opportunities, challenges, and implications. Am J Hum Genet 2010;86: 661-673

34. Wagner JK. Social and legal implications of DNA ancestry tests. PhD Thesis, Pennsylvania State University, 2010.

35. Jonassaint CR, Santos ER, Glover CM, et al. Regional differences in awareness and attitudes regarding genetic testing for disease risk and ancestry. Hum Genet 2010;128:249-260.

36. Wagner JK, Weiss KM. Attitudes on DNA ancestry tests. Hum Genet 2012;131:41-56.

37. Borges K. International Society of Genetic Genealogy. Session 3, 20 July 2010.

38. Parthasarathy S. Assessing the social impact of direct-to-consumer genetic testing: understanding sociotechnical architectures. Genet Med 2010;12:544-547.

39. American Society of Human Genetics. Ancestry testing statement. 13 November 2008. http://www.ashg.org/pdf/ASHGAncestryTestingStatement_FINAL. pdf. 